\title{
De Río Cuarto a Córdoba
}

\section{From Rio Cuarto to Córdoba}

\section{Nacha Vollenweider}

Nacha Vollenweider (Río Cuarto, Córdoba, Argentina, 1983) es licenciada en Pintura por la Universidad Nacional de Córdoba y magister en Arte (especializada en Ilustración y Diseño) por la Universidad de Ciencias Aplicadas de Hamburgo. Junto al guionista Roberto von Sprecher publicó Ruta 22 (Llantodemudo, Córdoba, 2010) y obtuvo el segundo lugar en la categoría de Historieta del vi Premio Centro Cultural de la Memoria Haroldo Conti por la obra Los otros. En 2013 fue becada por el Servicio Alemán de Intercambio Académico (DAAD) con una beca para artistas bajo el asesoramiento de la profesora Anke Feuchtenberger. En 2017 publicó su novela gráfica Fußnoten con la editorial alemana Avant-Verlag, también publicada en Argentina como Notas al pie (Maten al Mensajero, 2018) y en Francia (Editions Ilatina, 2019). Resultó seleccionada dos veces como finalista en el concurso de Novela gráfica alemana de la fundación Berthold Leibinger con sus proyectos Notas al pie y Volver (2016 y 2020). En 2019 publicó con HA Editora la historieta Tonga, a la vez que exhibió su trabajo en muestras colectivas en el Centro Cultural Kirchner y en la galería Hausrot en Köniz (Suiza), entre otros. Asimismo, en 2019 realizó sus primeras muestras individuales en Casa Suiza de La Boca «La Segunda» en Buenos Aires y «Diarios de Viaje» en la Casa de la Cultura de la ciudad de Río Cuarto. En 2020 publicó dos historietas cortas para los números 138 y 139 de la revista Strapazin (Zúrich, Suiza). En 2021 expuso junto al colectivo de dibujo callejero «Carbonillas Projekt» en el museo provincial de Bellas Artes y fue seleccionada con su obra «Islamiento» en el Bienal Nacional de Dibujo del Museo Franklin Rawson de San Juan. Publicó, también, La ley deMurphy (Maten al Mensajero) y «Vivas - Frauenbewegung in Argentinien» en el número 141 de Strapazin. Actualmente reside y trabaja en Río Cuarto y of rece diversos cursos en red de literatura dibujada.

Fecha de recepción: 29 de octubre de 2021

Fecha de aceptación definitiva: 5 de diciembre de 2021 
El presente cómic es una historieta que elaboré en el año 2019 para la revista cordobesa Las Fieras. El tema del número era «plantas». Se me ocurrió que podía ser interesante escribir sobre la problemática del agronegocio, la agroindustria y sus consecuencias.

Si partimos del dato de que la provincia de Córdoba en Argentina solo conserva el $3 \%$ de su bosque nativo, dejando lugar al avance de la frontera agrícola, podemos pensar en los niveles de depredación a gran escala para satisfacer necesidades de comercio de granos a escala global. El cómic es un pequeño recorrido por esta problemática que involucra directamente a los grandes monopolios como Bayer, BASF o Monsanto. Empresas monstruosas, que operan en todo el globo, vendiendo suplementos químicos para el control de la maleza y a la vez, cual dioses, creando un sistema de dependencia, modificando las semillas genéticamente para que únicamente funcionen con sus productos. Es decir, que aquí vemos cómo estas empresas no solo intentan controlar el futuro de la agricultura para satisfacer necesidades que poco tienen que ver con acabar con el hambre mundial sino que, a su vez, intentan hacer de la naturaleza una industria. Es decir, modificar el entorno natural para subsumirlo a un orden industrial. Un orden homogéneo, medible, controlable, mecanizando todos los procesos con el único objetivo de hacerlo más rentable. En el comic lo llamo el oro verde. Tampoco son empresas que evalúan los costos a largo plazo: la capacidad de regeneración de la naturaleza es cada vez menor si no hay bosques o si no hay suelos sanos. La naturaleza es vista como un objeto para hacer ganancias y no como un sistema. Los costos a largo plazo de esta manera de producir a nadie importan. Los números de casos de cáncer alrededor de los campos fumigados y la pérdida de biodiversidad parecen ser daños colaterales o zonas de sacrificio.

En este contexto existen, sin embargo, personas, lugares y espacios de resistencia. Resistencia a aceptar esta manera de producir, conociendo ya los aspectos negativos. En 2013 el municipio de Río Cuarto, mi ciudad natal, le negó a la multinacional Bayer/ Monsanto la instalación de una planta experimental de semillas dada la cantidad de ciudadanos que se oponían a este insalubre negocio. Al año siguiente la empresa comenzó un juicio contra la ciudad que, finalmente, en 2019 desiste de seguir ( $\underline{\text { https:// }}$ latinta.com.ar/2019/10/paz-social-rio-cuarto-monsanto-bayer-abandona-juicio/). Creo que ahora se fue a Chile. 


\section{DE RÍO CUARTO A CORDOBA}

NACHA VOIIENWEIDER
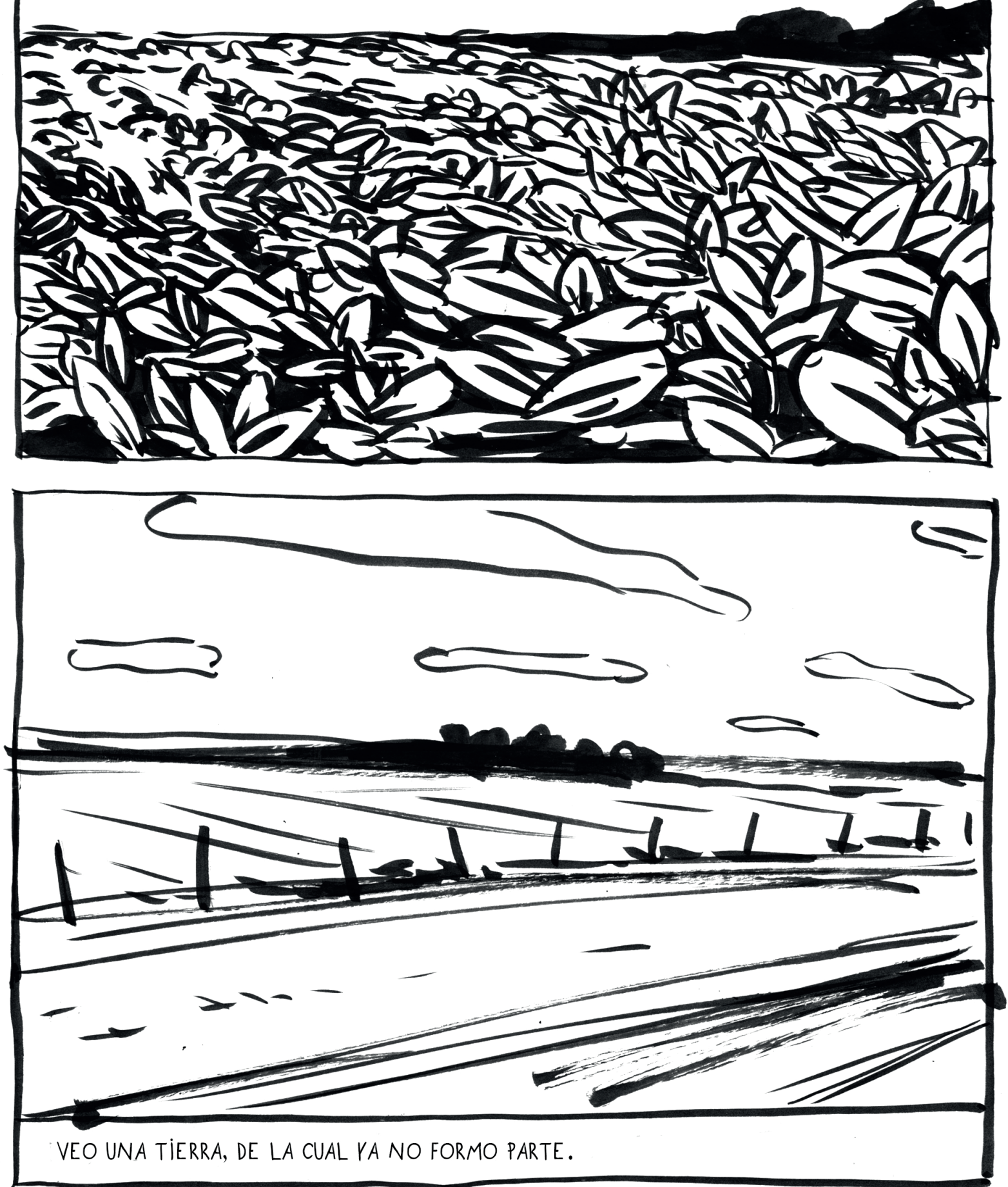

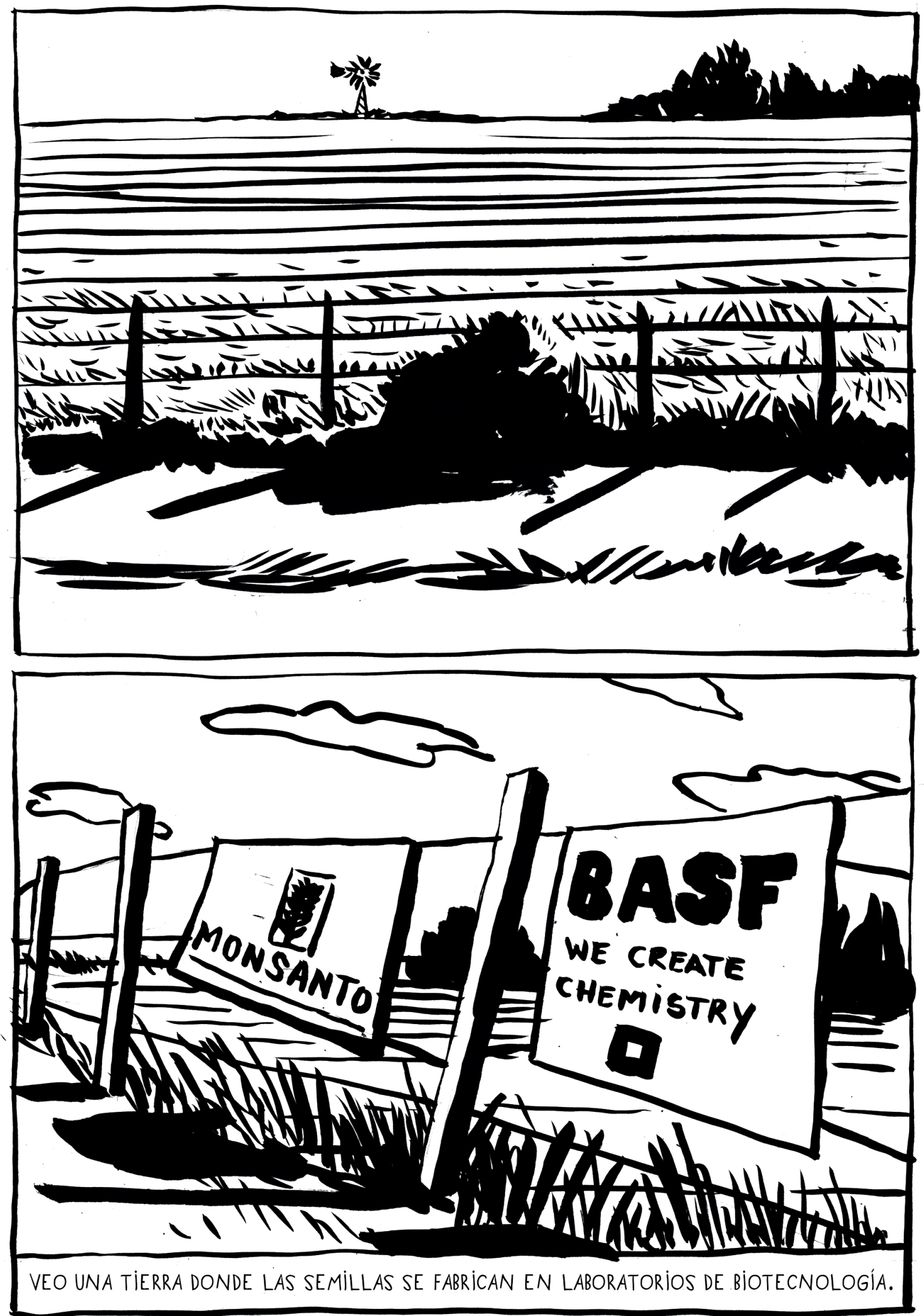

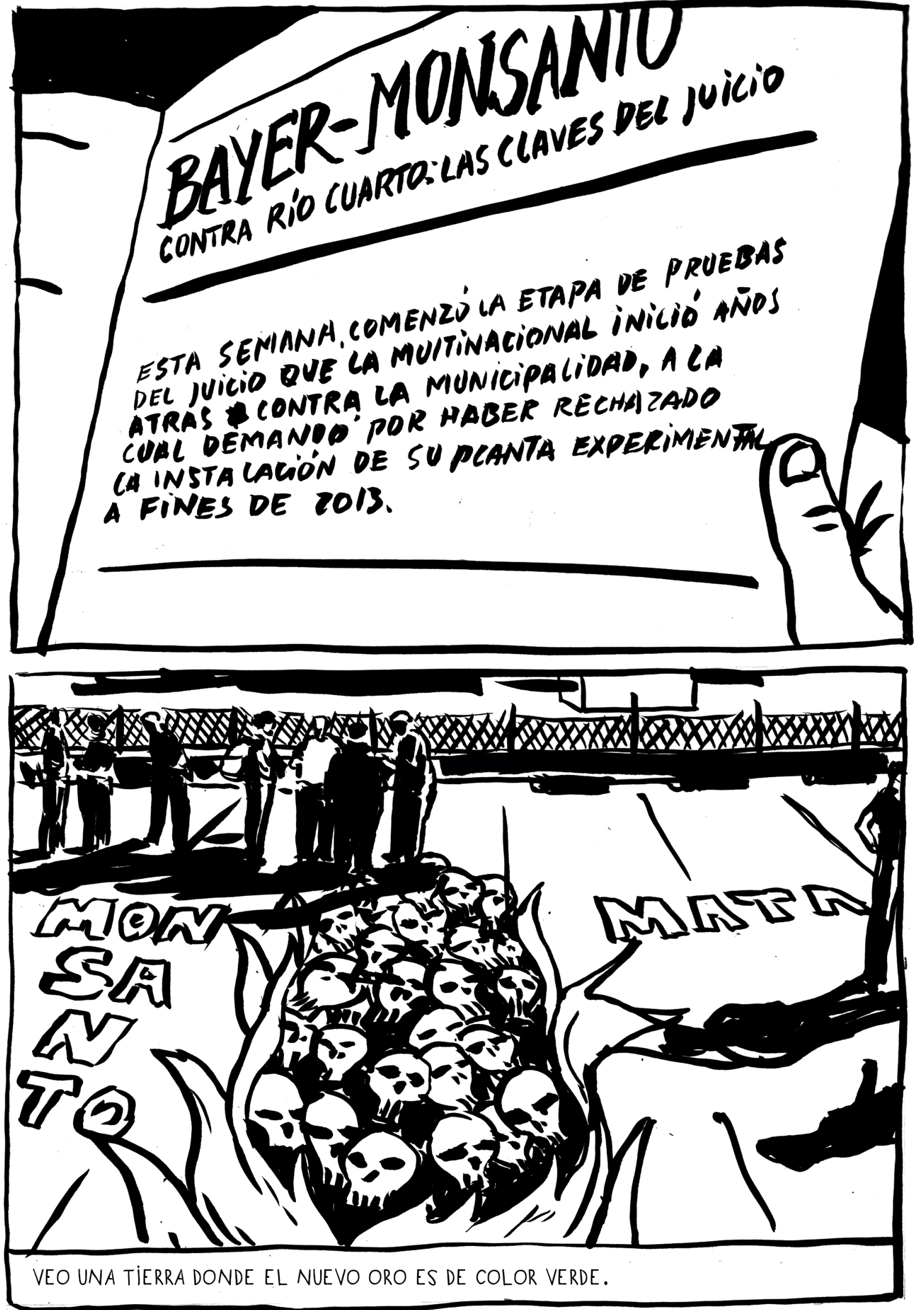